International Journal of Child, Youth and Family Studies (2016) 7(3/4): 456-471

DOI: http://dx.doi.org/10.18357/ijcyfs73-4201616169

\title{
THE PREVALENCE OF STUTTERING, VOICE DISORDER, AND SPEECH SOUND DISORDERS IN PRESCHOOLERS IN SHAHREKORD, IRAN
}

\author{
Omid Mohamadi, Mohammad Rahimi-Madiseh, and Morteza Sedehi
}

\begin{abstract}
The inability to communicate easily and clearly can have far-reaching debilitating effects, not only in childhood, but throughout a lifetime. The aim of this study was to determine the prevalence of stuttering, voice disorder, and speech sound disorders in Persian preschoolers in Shahrekord, Iran. Information about 1,387 children ages 5 to 6 was obtained via face-to-face screening and assessment. The total prevalence of speech disorders was $17.1 \%$. The prevalence of stuttering was $1.5 \%$, while $13.4 \%$ had a speech sound disorder, and $2.2 \%$ had voice disorder. The prevalence of stuttering was higher in males $(2.2 \%)$ than females $(0.7 \%)$; of speech sound disorders was higher in males (17.4\%) than females (9.1\%); and of voice disorder was higher in males $(2.6 \%)$ than females (1.6\%). The prevalence of stuttering and speech sound disorder was significantly different according to gender and positive family history. The prevalence figures revealed that a considerable number of preschoolers with speech disorders were missed in parents' and teachers' reports. Those children required more intensive communication support than they were receiving. Therefore, classroom teachers should work with speech and language pathologists to identify and assess preschoolers with communication disorders, and to develop intervention strategies.
\end{abstract}

Keywords: stuttering, speech sound disorder, voice disorder, preschoolers

Acknowledgements: The authors wish to thank all preschool centers in Shahrekord for their collaboration in conducting the survey. This study was supported by the Deputy for Research of Shahrekord University of Medical Sciences and Health Services, Shahrekord, Iran.

Omid Mohamadi (the corresponding author), Paramedical College, Shahrekord University of Medical Sciences, Shahrekord, I.R. Iran. Email: omohamadi8@gmail.com

Mohammad Rahimi-Madiseh, Pediatric Nursing at Shahrekord University of Medical Sciences, Shahrekord, I.R. Iran. Email: $\underline{\text { m_rahimi7@yahoo.com }}$

Morteza Sedehi, Statistics and Epidemiology at Shahrekord University of Medical Sciences, Shahrekord, I.R. Iran. Email: sedehi56@gmail.com 
International Journal of Child, Youth and Family Studies (2016) 7(3/4): 456-471

DOI: http://dx.doi.org/10.18357/ijcyfs73-4201616169

Determining the prevalence of communication disorders in children is important, both for planning appropriate interventions for affected children, and for proving the effectiveness of those interventions. Here, prevalence is defined as the "proportion or percentage of cases in a given population at a specified time” (Law, Boyle, Harris, Harkness, \& Nye, 2000, p. 166). Because the inability to communicate easily and clearly can have a debilitating effect on an individual's social and emotional well-being, not only in childhood, but in adulthood as well (Baker \& Cantwell, 1987), early identification of speech and language disorders and timely intervention are needed if the negative consequences of these disorders are to be averted (Ramey \& Campbell, 1984). As young children go about their lives with their families, in their day care centers or schools, and in their communities, the adequacy of their speech and language skills determines whether they can communicate effectively with adults and peers (Harrison, 2007). As McKinnon, McLeod, and Reilly (2007) pointed out, "Defining and describing communication disorders remains an inexact science because we lack clear and empirically derived definitions, cut-off points, and classification systems.” (p. 5). Consequently we lack a robust evidence base for identifying and managing speech and language disorders (Reilly, Douglas, \& Oates, 2004). However, it is clear that pre-school intervention is needed, as lifelong problems can result when childhood speech and language disorders are not addressed (Law, Boyle, Harris, Harkness, \& Nye, 1998).

Stuttering is a speech disorder that affects the rhythm and the continuous flow of speech. Its manifestations include "repetitions of syllables, part or whole words or phrases; prolongation of sounds; or blocking of sounds" (Craig \& Tran, 2005, p.41).Yairi and Ambrose’s (2005) screening study of more than 3,000 preschool children revealed a 2.43\% stuttering prevalence with no racial or ethnic differences. Karbasi, Fallah, and Golestan (2010) reported an estimate of $1.2 \%$ for stuttering in Persian primary school students. The prevalence of stuttering may vary greatly by age group, "from a high of approximately $1.4 \%$ for children 2 to 10 years of age to a low of roughly $0.37 \%$ for adults 51 years or older” (Johnson, 2007, p. 5). Soleimani, Mohammadi, Khasaei, and Ertiahi (2010) did not find any cases of stuttering in their study of 600 Iranian primary school children. McKinnon, McLeod, and Reilly (2007) provided a somewhat lower estimate of $0.33 \%$ for stuttering in children from kindergarten to Grade 6 . Johnson (2007) noted that:

Stuttering often develops in the preschool years and may resolve spontaneously, but may also persist throughout the lifespan. Individuals who stutter may be subject to negative stereotypes and be restricted in their social and vocational activities (Kroll \& Beitchman, 2005). (p. 6).

As Hooper (2004) explains, “According to Ramig and Verdolini (1998), voice disorders are generally characterized by an abnormal pitch, loudness, and/or vocal quality resulting from a disordered laryngeal, respiratory, and/or vocal tract functioning” (p. 320). Karbasi et al. (2010) 
International Journal of Child, Youth and Family Studies (2016) 7(3/4): 456-471 DOI: http://dx.doi.org/10.18357/ijcyfs73-4201616169

reported a prevalence of $0.47 \%$ for voice disorder in Persian primary school students. Boone and McFarlane (2000) stated that about 7\% of school-aged children experience continuing voice disorders; other studies estimate 6\% to 10\% (Boyle, 2000). Soleimani et al. (2010) obtained an estimate of $1.1 \%$ for voice disorder in Iranian primary school children. In an evidence-based study that reviewed the different methods used to describe voice disorders, Oates (2004) emphasized that confusion with regard to etiology and diagnosis makes prevalence studies more difficult.

Young children may exhibit problems in learning to pronounce various speech sounds correctly. A speech sound disorder (SSD) does not usually have an identifiable cause, such as a sensory (e.g., hearing), structural (e.g., cleft palate), or neurological (e.g., cerebral palsy) problem. As Johnson (2007, p.4) noted, "Children with speech sound disorders show a slowed rate of speech acquisition, but often follow a relatively typical sequence of sound development (Shriberg \& Kwiatkowski, 1994)”. Bowen (2011) stated that:

Dodd (1995, 2005) proposed a model with psycholinguistic underpinnings that is based primarily on linguistic profiling and speech subtypes. In it, specific speech subtypes are matched to discrete areas of psycholinguistic difficulty or breakdown that are "testable" or "differentially diagnosable". It embraces four subtypes that can occur at any age or stage of speech development, plus CAS [Childhood Apraxia of Speech]. They are: Phonological delay ... Consistent deviant phonological disorder ... Inconsistent Speech Disorder ... Articulation disorder ... Childhood Apraxia of Speech. (section 4).

Foy and Mann (2012) suggested that students with SSD are also at risk for reading disorders, while Skebo et al. (2013), under the subheading Reading Skills and Students with SSD, noted that "these students may have difficulty forming the phonological representations needed to acquire the speech sound system for spoken language and later for decoding (Lewis, Avrich, Freebairn, Hansen, et al., 2011)”. The majority of children (75\%) referred to speech and language pathologists (SLPs) for assessment have speech impairment (i.e., SSD; Mullen \& Schooling, 2010). Drawing on Law et al.’s (2000) summary of pre-1997 prevalence studies of speech sound disorders, Johnson (2007) noted that there were "no studies for children younger than age 5. Median estimates of prevalence for 5-, 6-, and 7-year old children were as low as $2.3 \%$ and as high as $14.5 \%$, probably reflecting the varied methods for identifying cases.” (p. 4). Campbell et al. (2003) reported a prevalence of $15.6 \%$ for SSD in 3-year-old children in a large, diverse community sample. Shriberg, Tomblin, and McSweeney (1999) obtained an estimate of 3.8\% for 6-year-olds. Karbasi et al. (2010) reported an estimate of 13.8\% for SSD in primary school students in Yazd, Iran. As noted by Johnson (2007), “McKinnon, McLeod, and Reilly (2007) used a conservative identification procedure that yielded an overall prevalence of $1.06 \%$ for SSD in 10,425 Australian school children from kindergarten to grade six.” According to Shriberg et al. (1994), "The lower prevalence rates at older ages are consistent with evidence that SSD may 
International Journal of Child, Youth and Family Studies (2016) 7(3/4): 456-471

DOI: http://dx.doi.org/10.18357/ijcyfs73-4201616169

resolve over time” (p. 4). Soleimani, Mohammadi, Khasaei, and Ertiahi (2010) reported a prevalence of $10 \%$ for articulation disorders in primary school children in Kermanshah, Iran.

To obtain accurate prevalence data for a particular speech disorder requires both an accepted definition of the disorder and a reliable method of diagnosis (Law et al., 2000). As Johnson (2007) notes, "Lifespan prevalence data are valuable in understanding the natural history, course, and prognosis of these disorders. Prevalence estimates also allow for assessment of possible risk and protective factors.” (p. 2). Ultimately, we need accurate prevalence figures across the lifespan for speech disorders. McLeod and Harrison (2009) stated that:

Identification of children with speech and language impairment becomes particularly critical around age 4-5 years, when parents and teachers consider their children's readiness for formal schooling. When able, diagnosis and intervention by a speechlanguage pathologist (SLP) is also sought at this time to ensure that the children will be maximally successful in their future educational and social endeavours. (p. 1214)

The current study presents prevalence data for stuttering, voice disorder, and SSD and its subtypes in Persian-speaking preschoolers in Shahrekord, Iran, where most of the 380,000 inhabitants use Persian as their common language. Knowing the prevalence of preschoolers with speech disorders will assist with the planning of early intervention programs in Iran.

\section{Method}

\section{Participants}

A total of 1,387 children, 706 boys (50.9\%) and 681 girls (49.1\%), were recruited as participants using a census method. These children participated in a descriptive cross-sectional study in Shahrekord in 2015. Data collection was conducted over a period of four months, from October to January. The children were from 34 preschool centers and ranged in age from 5 years and 2 months to 6 years and 3 months, with the majority (97\%) being between 5 years and 3 months and 6 years. The males and females did not differ by age. None of the children were on medications when they were tested, and all had met developmental milestones at age-appropriate levels. Children who had been diagnosed with other disorders such as hearing loss, mental retardation, neurological deficits, visual and physical impairments, and attention deficit hyperactivity disorders were excluded from the study. The parents and guardians of all the children had previously given consent for the records to be used for research purposes. The following information was collected for each child: date of birth, gender, birth order, maternal education level, hand dominance, and positive family history for speech disorders.

\section{Procedures}

Data collection was conducted with face-to-face screening and diagnostic tests. During screening, the children were asked to describe what was happening in three picture stories, and to read a poem that they had learned. Each of the three stories had four sequential pictures, taken 
International Journal of Child, Youth and Family Studies (2016) 7(3/4): 456-471 DOI: http://dx.doi.org/10.18357/ijcyfs73-4201616169

from books for children ages 5 to 6 . This screening tool was administered directly to each child during a 30-minute screening session. After screening, all children who showed signs of stuttering, voice disorder, or SSD were assessed by an SLP. The SLP used the Persian version of the Stuttering Severity Instrument-3 (SSI-3) for children who might stutter, the Persian Phonetic Information Test for children who might have SSD, and the Persian version of the Consensus Auditory-Perceptual Evaluation of Voice (CAPE-V) for children who might have a voice disorder.

The SSI-3 is one of the most reliable tools for measuring stuttering. Bakhtiar, Seifpanahi, Ansari, Ghanadzade, and Packman (2010) assessed the reliability of the SSI-3 for preschool Persian-speaking children who stutter. The Persian translation of SSI-3 has acceptable interjudge and intrajudge reliability (Bakhtiar et al., 2010). The SSI-3 comprises three weighted sections: (a) frequency, (b) duration, and (c) physical concomitants. A conversation of at least 300 syllables between each child suspected of having a speech disorder and his or her parent or guardian was recorded. The SLP then observed these videos to determine each child's actual frequency of stuttering. To obtain the duration score, at least 10 instances of stuttering were timed with a stopwatch to the nearest tenth of a second, and the duration of the longest three events was averaged. The last section required the SLP to rate each child on the presence of nonspeech behaviours: (a) distracting sounds, (b) facial grimaces, (c) head movements, and (d) movements of extremities. The SLP rated each observed behaviour on a 5-point scale ranging from 0 (none) to 5 (severe and painful-looking). The scores from the three subsections were totalled to create an overall score for each child.

The SLP used the Persian Phonetic Information Test to detect disordered pronunciation of sounds in preschoolers suspected of having SSD. The 2013 study by Ghasisin, Ahmadi, Mostajeran, Moazam, and Derakhshande showed that the phonetic test meets validity and reliability requirements and is sufficiently accurate to be used in the diagnosis and assessment of SSD in children. A booklet of pictures is used for the Phonetic Information Test. The SLP and the child sat in a calm environment, and the SLP asked the child to name the pictures. The child's speech samples were recorded and then assessed by the SLP.

In order to diagnose voice disorder in suspected preschoolers, the SLP used the Persian version of CAPE-V, which was assessed for validity and rater reliability by Salary Majd et al. in 2013. The SLP recorded voice samples of the child repeating six Persian sustained vowels, repeating six specially designed sentences, and conversing. The first task was for the child to say each vowel in his or her typical voice as steadily as possible until asked to stop, normally within 3 to 5 seconds. This was repeated three times. In the second task, the child either read the sentences one at a time from flash cards, or, if reading was a problem, the SLP read the sentence and the child repeated it. In the third task, the child responded to questions asked by the SLP, with the aim of having at least 20 seconds of speech to analyze. A score was then given for each vocal attribute. 
International Journal of Child, Youth and Family Studies (2016) 7(3/4): 456-471

DOI: http://dx.doi.org/10.18357/ijcyfs73-4201616169

\section{Data Analysis}

Data were analyzed using the Statistical Package for the Social Sciences (SPSS), Version 16.0. Descriptive statistics were used to determine the prevalence of speech disorders as recorded via direct assessments. A chi-square test was used for data analysis of qualities variables representing qualities. We considered differences significant at $p<0.05$.

\section{Compliance with Ethical Standards}

The authors declare that they have no conflict of interest. The study has been approved by the ethics committee of Shahrekord University of Medical Sciences. All procedures performed in this study were in accordance with the ethical standards of the Shahrekord University of Medical Sciences research committee. For each child in the study, informed consent was obtained from a parent or guardian. The parent or guardian gave written informed consent for the publication of any identifying details (name, date of birth, birth order, maternal education level, and other information about the children) that were deemed essential for the scientific purposes of this study.

\section{Results}

Overall, 21 children were identified as stuttering, 186 were identified as having SSD, and 30 were identified as having voice disorder (see Table 1). The combined prevalence of speech disorders in this population was estimated to be $17.1 \%$.

Table 1

Prevalence of speech disorder by type

\begin{tabular}{lcc}
\hline Speech Disorder & Frequency & $\begin{array}{c}\text { Prevalence in the population } \\
(\mathrm{N}=1387)\end{array}$ \\
\hline Stuttering & 21 & $1.5 \%$ \\
Voice disorder & 30 & $2.2 \%$ \\
Speech sound disorder & 186 & $13.4 \%$ \\
Total & 237 & $17.1 \%$ \\
\hline
\end{tabular}

\section{The Impact of Variables on Prevalence Figures}

Gender. Table 2 shows the prevalence of speech disorders by gender, with $11.5 \%$ of males and 5.5\% of females having speech disorders. The pattern of prevalence of stuttering and SSD differed significantly according to gender, with a higher prevalence of stuttering $(p=.025)$ and SSD $(p<.001)$ in males than in females. There was no statistically significant difference in prevalence of voice disorder between males and females $(p=.204)$. 
International Journal of Child, Youth and Family Studies (2016) 7(3/4): 456-471

DOI: http://dx.doi.org/10.18357/ijcyfs73-4201616169

Table 2

Prevalence of speech disorders by gender

\begin{tabular}{lcccc}
\hline Speech Disorder & Male & Female & $p$ & Total \\
\hline Stuttering & 16 & 5 & .025 & 21 \\
Speech sound disorder & 125 & 61 & $<.001$ & 186 \\
Voice disorder & 19 & 11 & .204 & 30 \\
Total (frequency) & 160 & 77 & & 237 \\
\% of total population & $11.5 \%$ & $5.5 \%$ & & $17.1 \%$ \\
(N=1387) & & & & \\
\hline
\end{tabular}

Subtypes of SSD. Table 3 shows the prevalence of different subtypes of SSD. The most common subtype was articulation disorder (AD; 7.6\%). Children with AD were unable to produce alveolar, bilabial, and glottal phonemes, most commonly in the pronunciation of /s/ and /z/ sounds (7.2\%) and least commonly in the pronunciation of bilabial and glottal sounds (0.1\%). Another subtype of SSD identified was phonological delay (PD; 5.8\%). Children with PD had phonological processes characteristic of children younger than their age.

Table 3

Prevalence of SSD subtypes

\begin{tabular}{lcccr}
\hline Type of phoneme & Subtype of SSD & Prevalence & Total Percentage & Number \\
\hline Alveolar (t,d,l,n,s,z) & AD & $7.4 \%$ & $55.3 \%$ & 103 \\
Bilibial (b,p,m) & AD & $0.1 \%$ & $0.5 \%$ & 1 \\
Glottal (h,?) & AD & $0.1 \%$ & $0.5 \%$ & 1 \\
Postalveolar (j,ch,zh,sh) & PD & $2.8 \%$ & $20.9 \%$ & 39 \\
Velar (k,g,y) & PD & $1.4 \%$ & $10.2 \%$ & 19 \\
Uvular (q,x) & PD & $0.7 \%$ & $5.3 \%$ & 10 \\
Labiodental (f,v) & PD & $0.9 \%$ & $6.9 \%$ & 13 \\
Total & & $13.4 \%$ & $100 \%$ & 186 \\
\hline
\end{tabular}

Positive family history. Table 4 shows the prevalence of speech disorders by positive family history (PFH). The prevalence of stuttering and SSD was higher in children who had a positive family history for these disorders compared with all other children $(p=.000)$.

Table 4

Prevalence of speech disorders by positive family history

\begin{tabular}{lcccc}
\hline Speech disorder & $\begin{array}{c}\text { Number of children } \\
\text { with PFH }\end{array}$ & $\begin{array}{c}\text { Number of children } \\
\text { without PFH }\end{array}$ & $p$ & $\begin{array}{c}\text { Prevalence in the } \\
\text { population (N=1387) }\end{array}$ \\
\hline Stuttering & 11 & 10 & $<.001$ & $1.5 \%$ \\
Speech sound disorder & 17 & 169 & $<.001$ & $13.4 \%$ \\
Voice disorder & 1 & 29 & .774 & $2.2 \%$ \\
Total & 29 & 208 & & $17.1 \%$ \\
\hline
\end{tabular}


International Journal of Child, Youth and Family Studies (2016) 7(3/4): 456-471

DOI: http://dx.doi.org/10.18357/ijcyfs73-4201616169

Maternal education level. Table 5 shows the prevalence of speech disorders by maternal education level. The maternal education level did not make a significant difference in the prevalence of speech disorders.

Table 5

Prevalence of speech disorders by maternal education level

\begin{tabular}{lccccr}
\hline Speech disorders & $\begin{array}{c}\text { Illiterate and } \\
\text { primary school }\end{array}$ & $\begin{array}{c}\text { Secondary and high } \\
\text { school }\end{array}$ & $\begin{array}{c}\text { Higher } \\
\text { education }\end{array}$ & $p$ & Total \\
\hline Stuttering & 1 & 12 & 8 & .388 & 21 \\
Speech sound disorder & 30 & 88 & 68 & .419 & 186 \\
Voice disorder & 8 & 12 & 10 & .734 & 30 \\
Total (frequency) & 39 & 112 & 86 & & 237 \\
\% of total population & $2.8 \%$ & $8.07 \%$ & $6.2 \%$ & & $17.1 \%$ \\
(N=1387) & & & & \\
\hline
\end{tabular}

Hand dominance. Table 6 shows the prevalence of speech disorders by hand dominance. Statistically, the frequency of speech disorders was not related to hand dominance.

Table 6

Prevalence of speech disorders by hand dominance

\begin{tabular}{lccc}
\hline Speech disorder & Right handed & Left handed & $p$ \\
\hline Stuttering & 19 & 2 & .744 \\
Speech sound disorder & 173 & 13 & .716 \\
Voice disorder & 28 & 2 & .764 \\
Total & 220 & 17 & \\
\hline
\end{tabular}

Birth order. Table 7 shows the prevalence of speech disorders by birth order. Statistically, the frequency of speech disorders was not related to birth order.

Table 7

Prevalence of speech disorders by birth order

\begin{tabular}{lccc}
\hline Speech disorder & First to third & Fourth or higher & $p$ \\
\hline Stuttering & 21 & 0 & .709 \\
Speech sound disorder & 182 & 4 & .687 \\
Voice disorder & 26 & 4 & .646 \\
Total & 229 & 8 & \\
\hline
\end{tabular}


International Journal of Child, Youth and Family Studies (2016) 7(3/4): 456-471

DOI: http://dx.doi.org/10.18357/ijcyfs73-4201616169

\section{Discussion}

It is important to note that a large proportion of preschool children in Iran have speech disorders, which may be associated with adverse, long-term outcomes that impact on individuals, families, and communities. According to McLeod and Harrison (2009):

Considerable variability has been noted in studies of prevalence in speech [disorders] ... The reasons for this variability include the definition of what constitutes a case, the severity and type of communication impairment that is included in the definition, the nature of the surveyed population, and differences in methodological procedures (Law et al., 2000; Pinborough-Zimmerman et al., 2007). Researchers have relied on three primary diagnostic methods: parent report, teacher report, and direct assessment by an SLP or trained research assistant. (p. 1214)

The aim of the current study was to determine the prevalence of stuttering, voice disorder, and SSD in 1,387 preschoolers by direct assessment. The prevalence of speech disorders in this population was estimated to be $17.1 \%$, which was higher than in investigations reported by Karbasi et al. (2010) on primary school students in Yazd, Iran (14.8\%) and by Soleimani et al. (2010) on primary school children in Kermanshah, Iran (11.2\%). A large part of this difference is due to the higher prevalence of lisp disorder (a subtype of articulation disorders that is characterized by bad pronunciation of /s/ and /z/ sounds) in the current study (7.2\%). Another major difference is related to the higher prevalence of voice disorder among the children in the current study (2.2\%). More detailed research would be required to determine whether cultural and regional differences or other factors are causing the higher prevalence of lisp disorder and voice disorder.

The total prevalence of speech disorders found in our study (17.1\%) was higher than that found in three Australian studies: Jessup, Ward, Cahill, and Keating's 2008 study of 308 children 5 to 6 years old (8.7\%); McKinnon et al.'s 2007 study of 10,425 children 5 to 12 years old (1.51\%); and Keating, Turrell, and Ozanne’s 2001 study of 12,388 children 0 to14 years old ( that $1.7 \%$ of children had childhood speech disorders). Similarly, the National Survey of Children's Health (United States Department of Health and Human Services, 2003) found a prevalence of 4.4\% for 5,071 American 8-year-olds. One probable reason for the higher prevalence in the current study is the differing methodologies employed. Typically, studies that use parent or teacher reports only (e.g., Keating et al., 2001), teacher reports followed by direct assessment (e.g., McKinnon et al., 2007), or telephone surveys (e.g., United States Department of Health and Human Services, 2003) will report lower prevalence figures than studies that use only face-to-face screening and assessment (e.g., the current study). Another likely reason for the higher prevalence figure in the present investigation is the age range of the children. The present study has much in common with the 2001 study by Okalidou and Kampanaros that reported the prevalence of communication disorders in children in Greece to be $14.4 \%$ to $18.7 \%$. Both studies collected data on a nearly equal number of children: the Okalidou and Kampanaros study 
International Journal of Child, Youth and Family Studies (2016) 7(3/4): 456-471 DOI: http://dx.doi.org/10.18357/ijcyfs73-4201616169

reported on 1,113 children; the present study on 1,387 children. The children in Okalidou and Kampanaros' study were slightly younger (kindergarten children) than those in the present study (preschoolers, aged approximately 5 to 6). In the present study, no significant association was observed between speech disorders and maternal education level, hand dominance, or birth order (Tables 5, 6, and 7); this finding agrees with the findings reported by Karbasi et al. (2010).

Overall, the estimated prevalence of specific speech disorders in the present study was higher than that of many previous investigations. The estimated prevalence of stuttering in the present study was $1.5 \%$. This is higher than the prevalence reported by Craig and Tran's 2005 study of 12,131 participants 1 to 99 years old (0.72\%); by McKinnon et al.'s 2007 study of 10,425 Australian children 5 to 12 years old (0.33\%); and by Van Borsel et al.'s 2006 study of 21,027 children 6 to 10 years old from regular schools in Belgium (0.58\%). The prevalence of stuttering was higher in children with a positive family history for this disorder compared with all other children (Table 4); this finding corresponds with the studies of Kraft and Yairi (2011) and Karbasi et al. (2010). In the present study, the estimated prevalence of voice disorders (2.2\%) was lower than the reported prevalence from Akif Kilic, Okur, Yildirim, and Guzelsoy's 2004 study of 617 school-aged children in Turkey (30.4\%); and from Duff, Proctor, and Yairi's 2004 study of 2,445 African American and European American children 2 to 6 years old (3.3\%); but higher than the reported prevalence from McKinnon et al.'s 2007 study of 10,425 Australian children 5 to 12 years old $(0.12 \%)$. The estimated prevalence of SSD in the present study (13.4\%) was higher than the prevalence of SSD reported by: McKinnon et al.'s 2007 study of children from kindergarten to Grade 6 (1.06\%); Shriberg et al.'s 1999 study of 6-year-old children (3.8\%); Keating et al.’s 2001 study of 12,388 children 0 to14 years old (1.3\%); and Beitchman et al.'s 2001 study (6.4\%); but much lower than the 43.9\% reported in Dudley and Delage's 1980 study. Again, these discrepancies may be due to differing methodologies employed and the age ranges of the participants. The prevalence of SSD was higher in children with a positive family history for this disorder compared with all other children (Table 4); this finding agrees with previous investigations by Campbell et al. (2003); Fox, Dodd, and Howard (2002); and Harrison and McLeod (2010). There are well-recognized differences in the reported incidence of stuttering at different ages, with a higher prevalence rate (1.44\%) reported for younger children, and a lower rate $(0.53 \%)$ for adolescents (Craig, Hancock, Tran, Craig, \& Peters, 2002). Data from longitudinal and cross-sectional studies suggest that SSD and stuttering decrease with age (Yairi et al., 2005). Studies that have acknowledged the decreasing incidence of communication disorders with age include Craig and Tran, 2005; Keating et al., 2001; Harasty and Reed, 1994; and Kirkpatrick and Ward, 1984.

In the present study, the ratio of males to females with SSD was 2.04:1. This significantly higher prevalence of SSD in males is similar to the findings of other studies of (a) the prevalence of SSD: Keating et al., 2001; Beitchman et al., 2001; Aithal et al., 1985; (b) the age of acquisition of speech sounds: Dodd, Holm, Hua, and Crosbie, 2003; McCormack, Harrison, 
International Journal of Child, Youth and Family Studies (2016) 7(3/4): 456-471

DOI: http://dx.doi.org/10.18357/ijcyfs73-4201616169

McLeod, \& McAllister, 2011; Smit, Hand, Frelinger, Bernthal, \& Bird, 1990; and (c) the risk factors for SSD: Campbell et al., 2003.

In this study, the ratio of males to females with stuttering was 3.2:1. This result was within the range of results reported by Bloodstein's 1995 summary of studies, with ratios from 2.2:1 to 6.3:1; and lower than McKinnon et al.'s (2007) ratio of 7.5:1. There are many reports in the literature of gender differences in development, with an increase in major psychosocial differences emerging with increasing age (e.g., Prior, Smart, Sanson, \& Oberklaid, 1993).

\section{Conclusion}

To summarize, $13.4 \%$ of the 1,387 preschoolers in this study were identified as having SSD, $2.2 \%$ were identified as having voice disorder, and $1.5 \%$ were identified as having a stutter. Identification occurred initially via face-to-face screening and was confirmed by evidence from speech-language pathology reports. The pattern of prevalence of stuttering and SSD was significantly different according to gender and positive family history. Birth order, maternal education level, and hand dominance made no significant difference to the pattern of prevalence across the three speech disorders. The data revealed that many preschoolers with speech disorders required more intensive communication support than they were receiving. Classroom teachers should work in consultation with speech and language pathologists to identify and assess preschoolers with communication disorders and to develop intervention strategies. As well, any collaborative team working on constructing educational programs for children with speech disorders in the wider educational community would benefit greatly from the inclusion of a speech and language pathologist. 
International Journal of Child, Youth and Family Studies (2016) 7(3/4): 456-471

DOI: http://dx.doi.org/10.18357/ijcyfs73-4201616169

\section{References}

Aithal, V. (1985). Prevalence of speech, language and hearing disorders. Hearing Aid Journal, 4(3), 68-73.

Akif Kilic, M., Okur, E., Yildirim, I., \& Güzelsoy, S. (2004). The prevalence of vocal fold nodules in school age children. International Journal of Pediatric Otorhinolaryngology, 68(4),409-412.

Baker, L., \& Cantwell, D. P. (1987). Factors associated with the development of psychiatric illness in children with early speech-language problems. Journal of Autism and Developmental Disorders, 17, 499-510.

Bakhtiar, M., Seifpanahi, S., Ansari, H., Ghanadzade, M., \& Packman, A. (2010). Investigation of the reliability of the SSI-3 for preschool Persian-speaking children who stutter. Journal of Fluency Disorders, 35(2), 87-91.

Beitchman, J. H., Wilson, B., Johnson, C. J., Atkinson, L., Young, A., Adlaf, E., ... Douglas, L. (2001). Fourteen-year follow-up of speech/language impaired and control children: Psychiatric outcome. Journal of the American Academy of Child and Adolescent Psychiatry, 40(1), 75-82.

Bloodstein, O. (1995). A handbook on stuttering (5th ed.). London, UK: Chapman \& Hall.

Boone, D. R., \& McFarlane, S. C. (2000). The voice and voice therapy (6th ed.).Boston, MA: Allyn and Bacon.

Bowen, C. (2011). Classification of children's speech sound disorders. Retrieved July 23, 2016 from http://www.speech-languagetherapy.com/index.php?option=com_content\&view=article\&id=45

Boyle, B. (2000). Voice disorders in school children. Support for Learning, 15(2), 71-75.

Campbell, T. F., Dollaghan, C. A., Rockette, H. E., Paradise, J. L., Feldman, H. M., Shriberg, L. D., ... KursLasky, M. (2003). Risk factors for speech delay of unknown origin in 3-year-old children. Child Development, 74(2), 346-357.

Craig, A., Hancock, K., Tran, Y., Craig, M., \& Peters, K. (2002). Epidemiology of stuttering in the community across the entire life span. Journal of Speech Language and Hearing Research 45(6), 1097-1105.

Craig, A., \& Tran, Y. (2005).The epidemiology of stuttering: The need for reliable estimates of prevalence and anxiety levels across the lifespan. Advances in Speech-Language Pathology, 7(1), 41-46. 
International Journal of Child, Youth and Family Studies (2016) 7(3/4): 456-471

DOI: http://dx.doi.org/10.18357/ijcyfs73-4201616169

Dodd, B., Holm, A., Hua, Z., \& Crosbie, S. (2003). Phonological development: A normative study of British English-speaking children. Clinical Linguistics and Phonetics, 17(8), 617643.

Dudley, J. G., \& Delage, J. (1980). Incidence des trouble de la parole et du langage chez les enfants Franco-Quebecois [Incidence of speech and language impairment in FrancoQuebecois children]. Human Communications/Communication Humaine, 5(Autumn),131142.

Duff, M., Proctor, A., \&Yairi, E. (2004). Prevalence of voice disorders in African American and European American preschoolers. Journal of Voice, 18(3), 348-353.

Fox, A. V., Dodd, B., \& Howard, D. (2002). Risk factors for speech disorders in children. International Journal of Language and Communication Disorders, 37(2), 117-132.

Foy, J. G., \& Mann, V. A. (2012). Speech production deficits in early readers: Predictors of risk. Reading and Writing, 25, 799-830.

Ghasisin, L., Ahmadi, T., Mostajeran, F., Moazam, M., \& Derakhshande, F. (2013). Evaluating the reliability and validity of phonetic information test in normal 5-6 year-old children of Isfahan city. Journal of Research in Reabilitation Sciences, 9(2), 153-160.

Harasty, J., \& Reed, V. A. T. (1994). The prevalence of speech and language impairment in two Sydney metropolitan schools. Australian Journal of Human Communication Disorders, 22(1), 1-23.

Harrison, L. J. (2007). Speech acquisition in a social context. In S. McLeod (Ed.), The International Guide to Speech Acquisition (pp. 78-85). Clifton Park, NY: Thomson Delmar Learning.

Harrison, L. J., \& McLeod, S. (2010). Risk and protective factors associated with speech and language impairment in a nationally representative sample of 4-to-5year-old children. Journal of Speech, Language, and Hearing Research, 53(2), 508-529.

Hooper, C. R. (2004). Treatment of voice disorders in children. Language, Speech and Hearing Services in Schools, 35, 320-326. Retrieved from https://libres.uncg.edu/ir/uncg/f/C_Hooper_Treatment\%20of\%20Voice_2004.pdf

Jessup, B., Ward, E., Cahill, L., \& Keating, D. (2008). Prevalence of speech and/or language impairment in preparatory students in northern Tasmania. International Journal of SpeechLanguage Pathology, 10(5), 364-377. 
International Journal of Child, Youth and Family Studies (2016) 7(3/4): 456-471

DOI: http://dx.doi.org/10.18357/ijcyfs73-4201616169

Johnson, C. J. (2007). Prevalence of speech and language disorders in children. In the Encyclopedia of Language and Literacy Development (pp. 1-10). London, ON: Canadian Language and Literacy Research Network. Retrieved from http://citeseerx.ist.psu.edu/viewdoc/download;jsessionid=8967432679B882DC9EC84BB70 7A9EB1A?doi=10.1.1.614.4792\&rep=rep1\&type=pdf

Karbasi, S. A., Fallah, R., \& Golestan, M. (2010). Prevalence of speech disorder in primary school students in Yazd-Iran. Acta Medica Iranica, 49(1), 33-37.

Keating, D., Turrell, G., \& Ozanne, A. (2001). Childhood speech disorders: Reported prevalence, comorbidity and socioeconomic profile. Journal of Pediatrics and Child Health, 37(5), 431-436.

Kirkpatrick, E., \& Ward, J. (1984).Prevalence of articulation errors in New South Wales primary school pupils. Australian Journal of Human Communication Disorders, 12(1), 55-62.

Kraft, S. J., \& Yairi, E. (2011). Genetic bases of stuttering: The state of the art, 2011. Folia Phoniatrica et Logopaedica, 64(1), 34-47.

Kroll, R., \& Beitchman, J. H. (2005). Stuttering. In B. J. Sadock \& V. A. Sadock (Eds.), Kaplan \& Sadock's comprehensive textbook of psychiatry (8th ed., pp. 3154-3159). Philadelphia, PA: Lippincott Williams \& Wilkins.

Law, J., Boyle, J., Harris, F., Harkness, A., \& Nye, C. (1998). Screening for speech and language delay: A systematic review of the literature. Health Technology and Assessment, 2(9), 1183.

Law, J., Boyle, J., Harris, F., Harkness, A., \& Nye, C. (2000). Prevalence and natural history of primary speech and language delay: Findings from a systematic review of the literature. International Journal of Language and Communication Disorders, 35(2), 165-188.

Lewis, B., Avrich, A., Freebairn, L., Hansen, A., Sucheston, L., Kuo, I, ... Stein, C. (2011) Literacy outcomes of children with speech sound disorders: Impact of endophenotypes. Journal of Speech, Language, and Hearing Research, 54(6), 1628-1643.

McCormack, J., Harrison, L. J., McLeod, S., \& McAllister, L. (2011). A nationally representative study of the association between communication impairment at 4-5 years and children's life activities at 7-9 years. Journal of Speech, Language, and Hearing Research, 54, 1328-1348.

McKinnon, D. H., McLeod, S., \& Reilly, S. ( 2007). The prevalence of stuttering, voice, and speech-sound disorders in primary school students in Australia. Language, Speech and Hearing Service School, 38, 5-15. 
International Journal of Child, Youth and Family Studies (2016) 7(3/4): 456-471

DOI: http://dx.doi.org/10.18357/ijcyfs73-4201616169

McLeod, S., \& Harrison, L. J. (2009). Epidemiology of speech and language impairment in a nationally representative sample of 4- to 5-year-old children. Journal of Speech, Language, and Hearing Research, 52(5), 1213-1229. Retrieved from http://www.health.sa.gov.au/Portals/0/Epidemiology of speech and language impairment in a nationally representative sample of 4- to 5-year-old children pt 1.pdf

Mullen, R., \& Schooling, T. (2010).The national outcomes measurement system for pediatric speech-language pathology. Language, Speech, and Hearing Services in Schools, 41, 4460.

Oates, J. (2004). The evidence base for the management of individuals with voice disorders. In S. Reilly, J. Douglas, \& J. Oates (Eds.), Evidence-based practice in speech pathology (pp. 110-139). London, UK: Whurr.

Okalidou, A., \& Kampanaros, M. (2001) Teacher perceptions of communication impairment at screening stage in preschool children living in Patras, Greece. International Journal of Language and Communication Disorders, 36(4), 489-502.

Pinborough-Zimmerman, J., Satterfield, R., Miller, J., Bilder, D., Hossain, S., \& McMahon, W. (2007).Communication disorders: Prevalence and co morbid intellectual disability, autism, and emotional/behavioral disorders. American Journal of Speech-Language Pathology, 16(4), 359-367.

Prior, M., Smart, D., Sanson, A., \& Oberklaid, F. (1993). Sex differences in psychological adjustment from infancy to 8 years. Journal of the American Academy of Child and Adolescent Psychiatry, 32(2), 291-304.

Ramey, C., \& Campbell, F. A. (1984). Preventative education for high risk children: Cognitive consequences of the Carolina Abecedarian Project. American Journal of Mental Deficiency, 88(5), 515-523.

Ramig, L. O., \& Verdolini, K. (1998). Treatment efficacy: Voice disorders. Journal of Speech, Language, and Hearing Research, 41, S101-S117.

Reilly, S., Douglas, J., \& Oates, J. (2004). Evidence based practice in speech pathology. London, UK: Whurr.

Salary Majd, N., Khoddami, S. M., Drinnan, M., Kamali, M., Amiri-Shavaki, Y., \& Fallahian N. (2014). Validity and rater reliability of Persian version of the Consensus Auditory Perceptual Evaluation of Voice. Audiology, 23(3), 65-74.

Shriberg, L.D., \& Kwiatkowski, J. (1994) Developmental phonological disorders: A clinical profile. Journal of Speech and Hearing Research, 37, 1100-1126. 
International Journal of Child, Youth and Family Studies (2016) 7(3/4): 456-471

DOI: http://dx.doi.org/10.18357/ijcyfs73-4201616169

Shriberg, L. D., Tomblin, J. B., \& McSweeney, J. L. (1999). Prevalence of speech delay in 6year-old children and co morbidity with language impairment. Journal of Speech, Language, and Hearing Research, 42, 1461-1481.

Skebo, C. M., Lewis, B. A., Freebairn, L. A., Tag, J., Ciesla, A. A., \& Stein, C. M. (2013). Reading Skills of Students With Speech Sound Disorders at Three Stages of Literacy Development. Language, Speech, and Hearing Services in Schools, 44(4), 360-373. doi:10.1044/0161-1461(2013/12-0015)

Smit, A. B., Hand, L., Frelinger, J. J., Bernthal, J. E., \& Bird, A.(1990). The Iowa Articulation Norms Project and its Nebraska replication. Journal of Speech and Hearing Disorders, 55, 779-798.

Soleimani, A., Mohammadi, H., Khasaei, H., \& Ertiahi, F. (2010). The prevalence of speech disorder among Kermanshah primary school children. Behbood Journal, 15, 213-219.

United States Department of Health and Human Services, Centers for Disease Control and Prevention, National Center for Health Statistics. (2003). National survey of children's health, 2003 (ICPSR04691-v1). Ann Arbor, MI: Inter-university Consortium for Political and Social Research [distributor]. doi:10.3886/ICPSR04691.v1

Van Borsel, J., Moeyaert, J., Mostaert, C., Rosseel, R., Van Loo, E., \& Van Renterghem, T. (2006). Prevalence of stuttering in regular and special school populations in Belgium based on teacher perceptions. Folia Phoniatricaet Logopaedica, 58(4), 289-302.

Yairi, E., \& Ambrose, N. A. (2005). Early childhood stuttering. Austin, TX: Pro-Ed. 